\title{
On the crystallized monohydrate of zinc
}

\section{M.J. Nicklès}

To cite this article: M.J. Nicklès (1848) On the crystallized monohydrate of zinc, Philosophical Magazine Series 3, 32:215, 315-317, DOI: 10.1080/14786444808645988

To link to this article: http://dx.doi.org/10.1080/14786444808645988

册 Published online: 30 Apr 2009.

Submit your article to this journal 준

Џll Article views: 2

Q View related articles $₫$ 
According to these statements, it will not be surprising to observe antimony and arsenic subject to the common law, and belong to the regular system, which appears really to be that of all the metals.Ann. de Ch. et de Phys., Janvier 1848.

\section{ON THE CRYSTALLIZED MONOHYDRATE OF ZINC. BY M. J. NICKLÈs.}

The author states that a mineral exists, and is known by the name of cupreous hydrate of zinc, which contains the hydrates of zinc and copper, and has the cleavages of a right rhombic prism; and wishing to know the relation it might bear to the artificial monohydrate of zinc, he prepared some of it to examine its crystalline form.

Runge was the first who observed the formation of crystallized hydrate of zinc on a pile, the elements of which, iron and zinc, were immersed in ammonia, potash or soda. Schindler found it to consist of -

$$
\begin{aligned}
& \text { Oxide of zinc....... } 81 \cdot 62 \\
& \text { Water ........... } 18.36
\end{aligned}
$$

These numbers agree with calculation, which requires 81.71 of oxide and 18.29 water. Two experiments gave M. Nicklès the same number.

'The process recommended by $M$. Runge is very simple. It is sufficient to introduce iron and zinc into a bottle containing either potash or ammonia; after some time, small crystals of the monohydrate are deposited on the sides of the bottle; very pure hydrogen gas is given out during the action.

This hydrate has the form of very limpid right rhombic prisms. When prepared from the zinc of commerce, these crystals frequently contain a black nucleus derived from the impurity of the zinc. This nucleus diminishes their limpidity, but renders the faces more reflective. The crystals are generally modified in the same manner. The summit is terminated by a bevil parallel to the great horizontal axis, and the lateral edges are generally truncated by a terminal face. It will be observed that these crystals belong to the same system as the hydrate of zinc and copper of mineralogists.

The author states that some observations were made by him during the preparation of the crystals, which he transcribes : the laminated zinc of commerce is more readily attacked than the fused metal: some of the latter was introduced into ammonia, with another portion of the same zinc laminated; the laminated zinc was dissolved in a short time, but the fused metal was hardly acted upon. When it is recollected that laminated zinc is denser than fused, the difference of solubility appears singular; but it is readily explained by considering the texture of both. In fact, when fused and cooled, zinc has a crystalline structure, which it loses completely by laminating; and it is well-known, that in general crystallized substances do not so readily dissolve as amorphous bodies.

The state of the iron employed also influences the energy of the reaction; but in this case it is the less dense metal which acts the best. Iron turnings favour the reaction, but laminated or forged 
iron retards it. In the first case the metal has not lost its crystalline structure; in the second all crystallization is destroyed. Moreover, the homogeneity of the surface must also diminish the influence of laminated iron.

It will be observed, that this opposition of effects is subordinate to the part which the metal ought to play in the reaction; for the zinc only dissolves, the iron serves merely as a negative pole.

The briskness of the action is measured by the hydrogen disengaged. 'This is abundant with ammonia, potash or soda, when laminated zinc and iron turnings are employed; but, on the contrary, it is more or less slow, according as the conditions are varied : 1 part of iron turnings, 3 parts of laminated zinc, and 300 cubic centimetres of solution of ammonia, yielded crystals in ten days; the iron did not dissolve, its action was constant, and it was requisite merely to replace the zinc from time to time as it disappeared.

The crystals are deposited wherever there are inequalities. They are very small if the action is rapid; but when it is moderately slow, they are very well-formed. They are always very brilliant when obtained with ammonia; when with potash or soda, they are entirely opake : this happens because the greater part of the hydrate of zinc is decomposed in these solutions, and a magma is deposited which contains but few crystals.

An experiment in which iron was replaced by lead, gave in four months rather large crystals, considering the quantity of ammonia employed.

In another experiment commenced the same day, there were employed ammonia, copper turnings and laminated zinc; after four months there were deposited large prisms upon the inequalities of the copper. It is to be observed, that during the whole of this time the ammonia did not become blue, and yet it was left exposed to the air. The author ascertained that in general the ammonia under these circumstances is not rendered blue in the air, if the two metals are completely immersed.

'This fact is so simple, that it is astonishing that it has not been long known. Finally, it belongs to the series of observations which Davy has made on the influence of saline solutions on copper. This metal, in fact, cannot be attacked by oxygen, when in the presence of a metal which is more electro-negative than it, in the medium under consideration.

This is so true, that if instead of zinc we make use of iron or tin, or of metals in fact which are negative in ammonia with relation to copper, the ammoniacal liquor becomes as blue in the air, at least as rapidly as if copper alone were employed.

The same does not occur if copper be immersed in a solution of zincate of ammonia in contact with the air, but without metallic zinc. The liquor, it is true, does not become coloured for some hours ; but in twenty-four hours small crystals of hydrate of zinc are formed*.

- If the arrangement be so made as not to immerse the whole of the copper in order to favour the absorption of oxygen, the precipitation is much more rapid and abundant; the monohydrate is deposited as a granular powder, mixed with a few crystals. 
The zinc has then been replaced by copper. If this ammoniacal solution of copper be agitated with zinc, this metal, conformably to its greater affinity for oxygen, will in its turn displace the copper, and it is precipitated upon the zinc in a very fine powder, and in a short time the liquor ceases to be blackened by sulphuretted hydrogen.

This, then, furnishes an example of reciprocal affinity which is worthy of attention, and from which chemical analysis may derive utility.-Ann. de Ch. et de Phys., Janvier 1848.

\section{ON THE HYDRATE OF CADMIUM. BY M. J. NICKLÈS.}

This hydrate may be obtained, like that of zinc, by means of am. monia, iron and cadmium, or by causing copper to act upon an ammoniacal solution of oxide of cadmium.

It is but slightly permanent, and is partially decomposed in the liquid in which it is formed. It would seem that this ready decomposition is owing to the energy of the reaction; at any rate the author has obtained it perfectly homogeneous, operating slowly by putting a strip of cadmium in communication with a bar of hardened iron, and immersing the whole in a $U$-shaped tube full of ammonia.

By allowing the ammoniacal mother-waters to stand, a fresh quantity of hydrate is deposited. If the surface of evaporation is great, it is deposited in flocculi; if, on the contrary, the evaporation takes place in an imperfectly corked bottle, it is formed in mammillated masses, with traces of crystallization; and this is the form in which the author has usually obtained it.

M. Nicklès had only a small portion of this substance for analysis. It yielded-

$$
\begin{array}{ll}
\text { Oxide of cadmium.... } & 89 \cdot 74 \\
\text { Water } \ldots \ldots \ldots \ldots & \frac{10 \cdot 26}{100 \cdot 00}
\end{array}
$$

Calculation requires 87.63 of oxide and 12.37 of water; the substance had therefore evidently undergone some change previous to analysis. - Ilid.

\section{ACTION OF ACIDS AND ALKALIES ON ASPARAGIN AND ASPARTIC ACID. BY M. PIRIA.}

The author obierves, that all chemists who have examined asparagin have observed the great tendency which it possesses to be de. composed by acids and alkalies, yielding ammonia and aspartic acid. M. Liebig states, even aspartic acid, when boiled in strong hydrochloric acid or fused with potash, is converted into ammonia and a new acid. M. Piria has arrived at a very different conclusion; he finding that neither hydrochloric nor sulphuric acid sensibly acts on aspartic acid, nor is any effect produced by nitric acid when free from nitrous vapour. Asparagin, on the other hand, is decomposed by various acids at a boiling heat, yielding ammonia, which combines with the acid employed, and free aspartic acid.

M. Piria found that crystallized asparagin, boiled for about an 